\title{
AS MÃOS
}

\section{NOTES ON THE HANDS}

\section{NOTES SUR LES MAINS}

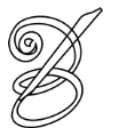 \\ Autor: \\ Antoine Berman \\ Traduzido por: \\ Simone PETRY* \\ Universidade Federal de Santa Catarina \\ Florianópolis, Santa Catarina, Brasil
}

Resumo: Este texto traça, de modo breve, minha trajetória acadêmica como tradutora e pesquisadora da área da teoria da tradução, iniciada na Universidade Federal do Paraná, no bacharelado em Letras com ênfase nos Estudos da Tradução. Também, como resultado desse trabalho de pesquisa, apresenta uma tradução inédita, para o português brasileiro, do ensaio poético As mãos, escrito pelo teórico da tradução Antoine Berman, publicado em 1969.

Palavras-chave: Tradução. Estudos da Tradução. UFPR. Antoine Berman. Théâtre d'Aran.

Abstract: This text briefly outlines my academic parcour as a translator and a researcher in the field of Translation Theory, which started during my undergraduate studies at the Federal University of Paraná (Bacharelado em Letras com ênfase nos Estudos da Tradução). It also presents, as a result of my most recent research work, a still unpublished translation, into Brazilian Portuguese, of the poetic essay Notes sur Le mains, written by the French translation theorist Antoine Berman, and published in 1969.

Keywords: Translation. Translation Studies. UFPR. Antoine Berman. Théâtre d'Aran.

Résumé: Dans ce texte, je vais d'abord présenter brièvement ma trajectoire universitaire en tant que traducteur et chercheuse dans le domaine de la théorie de la traduction, qui a commencé à l'Université Fédérale du Paraná (Bacharelado em Letras com ênfase nos Estudos da Tradução). Et puis, à partir de mes travaux de recherche les plus récents, je présenterai une traduction inédite en portugais brésilien de l'essai poétique Notes sur Les mains, écrit par le théoricien français de la traduction Antoine Berman et publié en 1969.

Mots clefs:Traduction. Traductologie. UFPR. Antoine Berman. Théâtre d'Aran.

RECEBIDO EM: 20 de setembro 2019

ACEITO EM: 25 de novembro 2019

PUBLICADO EM: março 2020 

urante a minha graduação em Letras com ênfase nos Estudos da Tradução, na Universidade Federal do Paraná (UFPR), foi quando me dei conta de que a Tradução, para além de uma importante atividade prática, poderia ser objeto poderoso de reflexão ao envolver em sua experiência diversas questões de extrema relevância a inúmeras áreas das ciências humanas, não se restringindo apenas a questões específicas do seu métier. A Tradução envolve um mundo de relações. Desse modo, já ali, teve início meu trabalho de pesquisa com teoria da tradução, passando pelo mestrado (orientada por Mauricio Cardozo), na mesma instituição, doutorado na Unicamp (orientada por Marcos Siscar) e na Universitè de Strasbourg (co-orientada por Jacob Rogozinski) e, por fim, o pós-doutorado na Universidade Federal do Rio Janeiro (UFRJ, com supervisão de Marcelo Jacques).

Também desde a graduação, venho me debruçando sobre a obra do importante teórico contemporâneo, Antoine Berman. Apesar de sua relevância para a área dos Estudos da Tradução e de sua presença constante nas pesquisas contemporâneas que tratam de questões de Tradução, tenho insistido na constatação de que sua obra ainda é pouco aproveitada com atenção à letra que nos oferece. Existe, especialmente, um trabalho de juventude do autor, ainda menos conhecido, e pouco acessível, que a meu ver, embora não trate de questões específicas de tradução, lança luz e dá um colorido todo especial para a compreensão de seu trabalho com a tradução e a teoria da tradução, ao qual ele se dedicou até o final de sua breve passagem por aqui.

Nesta publicação, apresento a tradução de um texto cujas características são muito presentes nos textos do jovem Berman, especialmente nos textos de antes de sua passagem pela América do Sul (entre 1970 e 1975), quando ele acabara de finalizar sua formação em filosofia e está profundamente envolvido com o pensamento do primeiro romantismo alemão, de Schlegel e Novalis principalmente, com a leitura de Rilke, e envolvido, também profundamente, em movimentos socialistas que se multiplicam, na época, embalados pelo evento de maio/68. Sua escrita, então, é permeada pela poesia, pela oralidade, pela fragmentação, pela mistura de vozes que reverberam reflexões, leituras, autores e os próprios dizeres do autor.

Em 1969, junto com sua esposa Isabelle Berman (que é diretora de teatro), põe em prática um de seus projetos que era a criação de um grupo de teatro, o Théâtre d'Aran, enquanto uma associação sem fins lucrativos, e que se apresenta na sua concepção pessoal do que entendia como um teatro verdadeiramente moderno. Em resumo, para ele, a modernidade, neste caso, residia no fato de as encenações conseguirem "escapar da tirania do texto e da 
escrita", mas sem abrir mão de um constante trabalho de escritura. Funcionava mais ou menos assim: eles escolhiam uma obra teatral, a partir dela era feito todo um trabalho de improvisação, elaborado pela direção e pelos atores do espetáculo, e um dos integrantes do grupo (que não era um grupo fechado, permitindo participações esporádicas) elaborava uma escrita de observação que poderia se apresentar como notas, esquemas de trabalho, poemas, críticas ou prosas livres. Essas observações anotadas, ou essa "reflexão poética da nossa experiência", como o grupo denominou, depois iriam retroalimentar os ensaios até o dia de sua apresentação ao público. Esses escritos também seriam publicados nos cadernos representando "o teatro dessa reflexão", ou a encenação escrita das reflexões geradas pela observação das improvisações.

Notes sur Les Mains, ou, As Mãos, como apresento aqui, é o resultado da reflexão de Antoine Berman a partir das improvisações silenciosas que viriam a compor o espetáculo L'Attente (A espera), ou L'Approche de Forgael (A aproximação de Forgael), criado a partir do texto Ombres sur la Mer (Shadowy Waters) de W.B. Yeats. Peça inspirada no folclore irlandês, bastante motivada pelo espiritualismo e misticismo de Yeats, e que narra a saga de marinheiros/piratas que estão há mais de 12 semanas em mar aberto, comandados por Forgael que, por sua vez, está ali a espera da chegada de um amor que virá do mar, e será completamente diferente do que qualquer outro amor que já existiu. O tema da espera pelo inalcançável, portanto, e os diferentes temas simbólicos que se desenrolam a partir dele, seriam o foco de inspiração para as improvisações do grupo de Berman.

Simone Petry 


\section{AS MÃOS}

(O Livro das Mãos deveria começar pela conexão das Mãos com o mais Longínquo. Elas carregam essa conexão duplamente: a palma e seu mapa mágico estão ligados aos astros e suas constelações; o dedo em riste, a mão levantada tem o poder inaudito de afastar ou de aproximar o céu).

1. Eu olhava minhas mãos, e de repente senti que elas também se olhavam, se sentiam, se desejavam e queriam brincar, impregnadas de um tipo de gravidade espirituosa (que as mãos, algumas vezes, podem

estar alegres).

Elas queriam estar sozinhas, como marionetes suspensas por um fio invisível que ignoram, como jovens bestas que se chacoalham, como gatos que se provocam amorosamente. Então, eu disse, corram para sua solidão, eu olho. E o jogo começa. A tendência de cada uma das mãos era evidentemente de se apoderar da outra; os dedos se contraiam como garras, se esticavam, e avançavam sem rodeios em direção aos outros dedos, mais sonhadores, mais descontraídos, que fugiam imediatamente e, nesse recuo, se mantinham numa cautelosa expectativa. Esqueci de dizer: a mão possessiva, com garras - a mão jogadora, portanto - era a mão direita. Tudo isso num ritmo perfeitamente lento, tão consumado, tão correto; não uma desaceleração, mas a entrada num universo onde toda gravitação, toda atração, são lentas... Não diríamos que $o$ ar no entorno dessas mãos pesadas tinha se tornado mais denso, mais compacto (sem por isso deixar de ser livre, um meio de liberdade), de modo a autorizar apenas gestos, abordagens muito, muito lentas; as duas mãos se aproximavam - com mil precauções, para nós incompreensíveis; lento também era o retorno à distância e à separação, ao passo que o encontro era um breve suspense, embora infinitamente doce. Nada ali pesava, nessas mãos, quando o corpo inteiro me parecia feito de chumbo, de uma imobilidade perturbadora e sem equilíbrio próprio. É como se o peso presente também nas minhas mãos tivesse se metamorfoseado, não em leveza, mas em gravidade benfazeja. As mãos estavam tão graves, elas deram tudo. O peso causava a lentidão que, por sua vez, reinava sozinha e recusava o peso. Daí, creio, o efeito, a essência poética desses gestos. Uma vinha por cima da outra, indiferentemente uma ou outra, agora a preensão e o medo da preensão tinham se dissipado, mas não era o mesmo com a inquietude. Elas não se conheciam, ou deviam se reencontrar - uma subia lentamente sobre o dorso da outra, sem 
tocar, explorava como uma besta explora: fareja, para, recomeça, prevê os perigos possíveis. Bruscamente - cada dedo convertido em antena - a mão esquerda partia, deslizando sob a sombra da palma. Seguia-se um tipo de dança, de movimento muito terno, muito doce - em ambas - que significava provavelmente a exigência de um novo encontro e o ensaio de um outro contato. Mas não de imediato, seria preciso esperar, e rodopiar um pouco mais por si só.

Era verdadeiramente "o mundo visto do fundo do mar", ali onde dormem as lentidões mais silenciosas... E se a direita tentasse seja debruçar-se sobre a esquerda ou - uma vez mais - agarrá-la (coisa insensata, impossível), a esquerda escapava delicadamente, com uma vontade que não carregava mais nenhum traço de medo, apenas a recusa de ser agarrada de modo tão bárbaro ali onde a situação não exigia de maneira nenhuma, até mesmo proibia, qualquer violência, qualquer transgressão do jogo. Mas ao mesmo tempo em que ela se retraía, era tomada pelo desejo de voltar atrás e de se aninhar no interior da mão direita, apesar do risco que corria. Então, o interior surgia, fabuloso, e teríamos nos dado tão bem nessa caverna sombria, teríamos mesmo esquecido os dedos formidáveis a nossa volta. Não é assim que nos perdemos? Ou que, às vezes, nos salvamos? Depois, parece que ambas as mãos tinham compreendido que um outro contato era possível - o mesmo, na verdade, mas transformado: outra vez a mão direita se debruçava delicadamente sobre a mão esquerda (que tremia de - sei lá o que - com um bocadinho de medo), com tamanha delicadeza que o desconforto da outra desaparecia muito rápido, a ponto dela pedir um contato, mesmo, ou sobretudo, muito breve. E isso era - não permitido (por quem?), mas dado - o breve roçar de dedos (que para mim, por outro lado, parecia longo, longo, muito longo para as leis deste espaço... Mas eu estava enganado: tudo estava como deveria estar). Assim acariciada, a mão esquerda (no fundo, ambas estavam se tornando peixes) começava a se comover, a escapar da imobilidade que a aprisionava: o desejo da outra mão a libertava. Ela deslizava sobre o dorso da mão direita delicadamente, bem delicadamente, e lentamente se preparava para cobri-la como uma sombra de mão, mais terna e mais leve. E se a mão viril no início se inquietava com esta sobreposição, foi logo vencida por essa sábia delicadeza que crescia sobre ela; veio um apaziguamento, um consentimento, uma total pureza; e pela primeira vez passava pelas duas uma corrente indescritível, um fluido invisível que deixou para traz tudo o que havia se passado... 
oh,

escrever na palma,

nos seus sulcos,

esses cortes, essas linhas,

essas ribeiras sem água,

esses desertos

2. E como a carícia parece difícil! Não é simplesmente colocar a mão sobre a mão: assim nada se produziria. É preciso deixar acontecer. Há tudo o que chamamos de aproximação, de busca, etc. Está tão próxima, a mão; sobretudo para a outra mão (nós, nossas mãos, nos são muitas vezes estrangeiras, retornarei a isso). Porém, não mais próxima que o céu, ou que o anel de R. E mais próximas do céu do que de nós mesmos, pois elas estão em correspondência absoluta com o Longínquo, o Astral (veja as "linhas" da mão, todo o conhecimento titubeante que se construiu sobre isso significa algo. Eis aí o lugar do corpo que é como fissurado, entrecortado, atravessado por todos os rios, todas as artérias da vida e do destino. Talvez saibamos apenas uma coisa: que esse mapa da palma está profundamente ligado aos astros, e que podemos lê-lo como se lê um mapa celeste: lemos, estabelecemos relações, mas nada ali está dado). Eu dizia: as mãos correspondem ao Longínquo, não a nós (que as utilizamos sem fazer uso de seus altos poderes, exceto na feitiçaria e na maldição). E aquele que ergue as mãos em direção ao céu, fique atento, que ele sonda seu "coração": rezar ao céu, abri-lo pela amplitude e divindade dos seus gestos, abri-lo e glorificá-lo por esta abertura - ou blasfemálo! Às vezes me parecia que um simples gesto - abrir suas duas mãos em um SIM vertiginoso - me daria o mundo e, além disso, ajudaria o mundo a ser mundo. Como se as mãos ( e talvez todo o corpo) tivessem o poder de liberar, senão de criar espaço (quando Rilke fala de "espaço-interior-do-mundo" se trata de um espaço que projetamos, liberamos à nossa volta, que tornamos mais intimamente espaçoso, mais intenso). Dar intensidade, profundidade ao espaço para que ele não seja um simples meio, uma simples exterioridade vazia. Ar, ar: não difícil, fácil, nós o criamos! Um olhar, uma mão erguida... Tanto espaço determinado por um olhar que não é espera, mas simples instância (a espera força, o que não é bom; a instância é mais modesta, parece nada pedir e, ainda assim, arde; a instância está aí, simplesmente. Daí o espaço vem, sem medo). E uma mão erguida, como uma pedra erguida, multiplica o Aberto, o intensifica. Os arabescos dos gestos e dos olhares fazem e desfazem o espaço: é preciso a 
maior das forças para isso. Que essas mãos estelares nos sejam com tanta frequência estrangeiras, está claro agora.

Mas o que vale para a mão, vale também para o corpo. Estranho devolver os corpos a sua solidão primeira, entregá-los à aventura da solidão - Solidão poética: entregue e aberta à influência dos outros corpos, dos astros que são esses corpos.

Qual seria, aqui, a primeira palavra? Eu sonho, eu espero ansiosamente por esta primeira palavra, esta interrupção do Verbo e do Nome.

quarta feira 5 de março.

\section{REFERÊNCIA}

BERMAN, Antoine. Notes sur les Mains. In: Les cahiers d'Aran, $\mathrm{n}^{\circ} 1$. Revista trimestral do Teatro de Aran. Paris, 1969. Tradução de: Notes sur les Mains. ${ }^{1}$

\footnotetext{
* Simone Christina PETRY - Bacharel em Letras - Português/Italiano com ênfase em Estudos da Tradução (2006) pela Universidade Federal do Paraná. Mestre em Letras (2011) pela mesma instituição. Doutora em Teoria e História Literária (2016) pela Universidade Estadual de Campinas. Realizou pesquisa de pós-doutorado (2018-2019) na Universidade Federal do Rio de Janeiro. Pós-doutoranda na Universidade Federal de Santa Catarina. Universidade Federal de Santa Catarina, Centro de Comunicação e Expressão, Programa de PósGraduação em Estudos da Tradução. Florianópolis, Santa Catarina, Brasil.

Currículo acadêmico: http://lattes.cnpq.br/5867821663351559

ORCID: https://orcid.org/0000-0001-8123-6530

E-mail: petry.simone@gmail.com

1 A tradução deste texto foi autorizada em 17/09/2019 por Isabelle Garma-Berman, detentora dos direitos autorais da obra de Antoine Berman, bem como diretora responsável tanto pelo extinto grupo Le Théâtre d'Aran quanto pela, também extinta, revista Les Cahiers d'Aran.
} 